\title{
FRONTEIRAS E \\ IMPÉRIOS NA \\ AMAZÔNIA IBÉRICA
}

\section{Carlos Augusto Bastos'}

Universidade Federal do Amapá (Unifap)

Macapá - Amapá - Brasil

Resenha do Livro: GÓMEZ GONZÁLEZ, Sebastián. Frontera selvática: Españoles, portugueses y su disputa por el noroccidente amazónico, siglo XVIII. Bogotá: Instituto Colombiano de Antropología e Historia - ICANH, 2014, 399 p.

A historiografia brasileira sobre a região amazônica, de um modo geral, ainda privilegia uma visão centrada na dimensão local ou regional desse espaço, ignorando as dinâmicas históricas em curso nas zonas limítrofes no extremo norte da América do Sul. Com relação ao período colonial, no entanto, uma visão mais atenta para a produção acadêmica sobre as outras "Amazônias" (áreas sob a administração de espanhóis, franceses, holandeses e ingleses) permite traçar comparações com processos políticos, econômicos, sociais e culturais que ocorriam no lado português. Além de comparações, abordagens historiográficas para além dos limites imperiais/nacionais podem ense-

1 Doutor em História pela Universidade de São Paulo em 2013. Professor de História da América na Universidade Federal do Amapá - Unifap. carlobastos@unifap.br. 
jar pesquisas sobre as inter-relações e conexões existentes entre os diferentes empreendimentos coloniais que dividiram essa vasta fronteira sul-americana.

Uma obra que desenvolve tal enfoque com excelência é o livro Frontera selvática, do historiador colombiano Sebastián Gómez González, professor do Departamento de História na Universidad de Antioquia, Colômbia. A obra é uma versão levemente alterada de sua tese de doutorado intitulada La frontera selvática. Historia de Maynas, siglo XVIII, defendida em 2012 no programa de Estudios Latinoamericanos de la Facultad de Filosofía y Letras da Universidad Autónoma de México (Unam), sob a orientação do prof. dr. Antonio García de León. Publicado em 2014, o livro recebeu o prestigioso Premio Nacional a la Investigación en Historia, outorgado pelo Ministério da Cultura da Colômbia e pelo Instituto Colombiano de Antropología e História (ICANH).

Em sua investigação sobre as fronteiras amazônicas (o noroccidente, segundo denominação mais comum para o período) do novo Reino de Granada no século XVIII, Sebastián Gómez coletou farta documentação primária em arquivos na Colômbia, Equador, Espanha, Itália e Portugal, lançando mão ainda de um conjunto amplo de fontes cartográficas e impressas. Além de um trabalho de fôlego no levantamento e análise da documentação, o autor abarcou uma produção historiográfica considerável sobre as possessões espanholas e portuguesas na Amazônia no período colonial, bem como estudos gerais sobre os impérios ultramarinos espanhol e luso, dialogando com obras consagradas e trabalhos mais recentes publicados nos países de língua espanhola, em Portugal e no Brasil. Deve-se ainda destacar a análise que Gómez realiza da literatura acadêmica sobre fronteiras, tema que recebeu atenção de diferentes áreas das ciências sociais e produziu estudos referenciais no campo da história.

O estudo de Sebastián Gómez enfoca a Província de Maynas, área na bacia amazônica fronteiriça aos domínios portugueses, a qual fez parte da Audiência de Quito (e, por conseguinte, do Vice-Reino de Nova Granada) do século XVI ao início do XIX, quando então essa circunscrição territorial foi incorporada ao Vice-Reino do Peru. Dentro de uma produção acadêmica que privilegia os espaços andinos e litorâneos, o trabalho de Gómez González sobre o noroccidente amazônico da América espanhola preenche uma lacuna historiográfica, inserindo esta região de fronteira em debates e questões que orientavam as políticas coloniais para outras partes do ultramar hispânico. Trata-se, de fato, de uma fronteira ainda pouco visitada pelos historiadores que se dedicam ao mundo colonial hispano-americano, se compararmos a historiografia sobre a bacia amazônica sob a jurisdição espanhola com a volumosa bibliografia disponível sobre as fronteiras platinas ou o norte do 
Vice-Reino da Nova Espanha, por exemplo. Em sua análise, o autor, ao tratar de uma área tradicionalmente considerada como um "vazio" e de importância marginal, objetiva entender os impactos de questões geopolíticas mais amplas dos impérios ultramarinos na fronteira amazônica, o que significa também lançar novas luzes sobre o enorme conjunto de territórios incorporados à Coroa espanhola.

As políticas das autoridades espanholas para essa zona limítrofe foram marcadas por avanços e recuos, pressionadas pelas incursões militares e comerciais de portugueses, por rebeliões locais de indígenas e pelas difíceis condições físicas que a topografia amazônica impunha ao sucesso dos projetos defensivos e econômicos coloniais. A análise dos diferentes (e, em grande medida, frustrados) projetos de incorporação de Maynas ao restante dos domínios hispano-americanos leva o autor a adotar um enfoque de longa duração em seu trabalho. O recorte temporal do estudo compreende principalmente o período de 1700 a 1777, ressaltando-se nesta cronologia alguns marcos fundamentais, como o início da Monarquia dos Bourbons no alvorecer dos Setecentos, o Tratado de Madri de 1750 e o de Santo Ildefonso no ano de 1777, enfatizando-se a inserção da fronteira luso-espanhola de Maynas nesse quadro geral. Ao mesmo tempo em que situa as demandas e interferências mais amplas das disputas imperiais nessa fronteira, Sebastián Gómez chama a atenção para as dinâmicas mais locais, isto é, as estratégias dos sujeitos que habitavam a Província de Maynas no sentido de sustentar as pretensões territoriais que opunham espanhóis a portugueses. Nesse sentido, o jogo de análise adotado pelo autor, entrelaçando na mesma narrativa a exposição do quadro geral e a interpretação das ações e posicionamentos dos sujeitos locais, constitui um dos grandes méritos do trabalho.

A divisão dos capítulos do livro segue recortes cronológicos menores, procurando entender conjunturas específicas da fronteira luso-espanhola em questão. O capítulo primeiro da obra, de fato, antecede o recorte principal do estudo, abordando os primeiros passos da incorporação da área amazônica da Audiência de Quito aos domínios espanhóis e a organização inicial da Província de Maynas. Este capítulo introdutório apresenta as primeiras expedições de conquista das selvas setentrionais ao oriente dos Andes, no século XVI, uma região inóspita e apartada dos principais estabelecimentos coloniais representados por cidades como Cusco, Lima, Quito, Popayán e Santa Fé. A expansão das frentes coloniais de penetração e incorporação territorial logo se viu contida por revoltas de populações indígenas da selva, com destaque para os índios jívaros, criando assim obstáculos a 
largo prazo para a fundação de povoações espanholas e a concretização de expectativas de exploração econômica daquelas terras.

No começo do século XVII, essas zonas permaneciam praticamente como espaços desconhecidos para as autoridades espanholas da América meridional. Apenas em 1618 a Província de Maynas, território que compreendia a fronteira oriental com as terras portuguesas no vale amazônico, teve seu primeiro governador nomeado. No entanto, as décadas iniciais desse século foram marcadas pelas primeiras incursões bem sucedidas de portugueses sobre a fronteira, tema este explorado por uma historiografia mais tradicional que exalta a penetração lusa no vale amazônico a despeito da subordinação de Portugal a Castela durante a União Ibérica (1580-1640). ${ }^{2}$ Em contraposição aos movimentos portugueses rumo às proximidades das terras andinas, Gómez destaca a ação missioneira como a mais efetiva medida de defesa dos interesses da Monarquia hispânica na região, ${ }^{3}$ o que deixava à mostra as tensões e contradições existentes na União Ibérica, as quais reverberavam com força nas fronteiras amazônicas. A partir da década de 1640, com a restauração da Monarquia portuguesa, ganha força o discurso de fechamento daquela fronteira aos avanços e contatos com os súditos portugueses, medidas que, na verdade, foram muito pouco efetivas. Igualmente frustrados foram os projetos espanhóis de incorporação daquela região a rotas comerciais mais dinâmicas, as quais supostamente fariam de Maynas um ponto estratégico da ligação dos Andes ao Atlântico através dos rios amazônicos. Outras expectativas nutridas por autoridades laicas e eclesiásticas que serviam em Maynas, como inversões de recursos na defesa militar contra os portugueses, também não foram realizadas, o que contribuía para

\footnotetext{
${ }^{2}$ Conferir REIS, Arthur Cezar Ferreira. A política de Portugal no vale amazônico. Belém: Secult, 1993.

3 O protagonismo missionário na ocupação da fronteira amazônica da América espanhola tem sido ressaltado por outros estudos, bem como as dificuldades enfrentadas na região pelos religiosos frente às investidas luso-americanas. Sobre esta produção historiográfica, conferir: ESPINOZA, Waldemar. Amazonía del Perú: História de la Gobernación y Comandancia General de Maynas (Hoy regiones de Loreto, San Martín, Ucayali y Provincia de Condorcanqui). Lima: Fondo Editorial del Congreso del Perú, 2007; MARTIN RUBIO, Maria del Carmen. Historia de Maynas, Un paraíso perdido en el Amazonas. Madri: Ediciones Atlas, 1991; NEGRO, Sandra. Maynas, una misión entre la ilusión y el desencanto. In: NEGRO, Sandra \& MARZAL, Manuel. Un reino en la frontera: Las misiones jesuitas en la América colonial. Quito: Abya-Yala, 2000, p. 185-203; PORRAS P., Maria Elena. Gobernación y Obispado de Mainas, siglos XVII-XVIII. Quito: Ediciones Abya-Ayala, Taller de Estudios Historicos, 1987; ROSAS MOSCOSO, Fernando. Del rio de la Plata al Amazonas: El Perú y el Brasil en la época de la dominación ibérica. Lima: Universidad Ricardo Palma, 2008.
} 
fragilizar a presença dos missionários que estavam em Maynas a serviço de sua majestade católica.

O segundo capítulo inicialmente situa os conflitos nos limites luso-espanhóis na bacia amazônica no conjunto dos choques que envolveram Portugal e Espanha durante a Guerra de Sucessão (1701-1713). Nesse sentido, Sebastián Gómez insere a zona fronteiriça de Maynas com a América lusa no marco das disputas diplomáticas e militares que envolviam Portugal e Espanha, deixando claro que não se tratava de uma parte desconectada das tensões internacionais que abarcavam os dois impérios. As penetrações portuguesas em Maynas ganham fôlego nos anos iniciais do XVIII, ao passo que as missões espanholas se firmam como a medida mais efetiva de defesa da soberania de Castela na área. Ao longo desse século, a produção documental dos padres nas missões é particularmente rica para a análise da situação da fronteira e das rivalidades imperiais, contestando as pretensões jurídicas de Portugal sobre a fronteira norte e revelando os temores de uma iminente invasão portuguesa. Nas considerações de muitos religiosos estabelecidos em Maynas, o avanço de embarcações vindas da América lusa não representava um risco apenas pela prática do contrabando, escravização de índios e destruição dos estabelecimentos missionais. Mais do que isso, essas investidas poderiam colocar em risco a soberania espanhola na parte amazônica e mesmo nas cobiçadas terras andinas contíguas, dadas as vantagens militares e comerciais que os lusitanos usufruíam a partir daquela fronteira, o que poderia alterar drasticamente a correlação de forças das coroas ibéricas no continente. Nas interpretações gestadas a partir de Maynas, fazia-se necessário ter acesso a informações do lado português da fronteira por meio da espionagem, bem como sobre o movimento dos ingleses, aliados de Portugal, em outros pontos da América, de modo a prever uma possível ação conjunta direcionada para aquela fronteira. Em 1711, uma invasão portuguesa se concretizou, desprotegendo os espanhóis nos limites noroccidentales ao desmantelar estabelecimentos missionários em Maynas, deixando a fronteira em um estado absolutamente móvel no início do século XVIII, como observa o autor.

Segundo Sebastián Gómez, as incursões vindas da parte portuguesa da fronteira evidenciavam a fragilidade das defesas militares espanholas em Maynas. A fundação de uma casa forte portuguesa no rio Napo na década de 1730 significou um passo a mais a favor da presença lusa na área, funcionando como um enclave militar e comercial direcionado para as terras hispano-americanas. Essas medidas visavam concretizar não apenas o avanço territorial, mas também a manutenção de redes de comércio ligando a cidade portuária de Belém às cidades andinas por meio do 
contrabando na bacia amazônica, alimentando o sonho dos portugueses de abertura de novas rotas de acesso à prata espanhola. Os projetos das autoridades espanholas, em contraposição às ameaças vizinhas, objetivavam incorporar Maynas a rotas comerciais com zonas andinas e fundar povoações em pontos estratégicos para defesa, medidas que não se concretizaram em virtude das dificuldades de comunicação com a fronteira e de reunião da população indígena em novos estabelecimentos. Na conjuntura da década de 1730, o autor destaca que as tensões surgidas na faixa fronteiriça não estavam diretamente relacionadas à situação diplomática experimentada pelas duas coroas ibéricas. Esse foi um período, na verdade, de relativa estabilidade das relações luso-espanholas, indicando assim que as interações mantidas pelos sujeitos no espaço da fronteira não podem ser entendidas como reflexos diretos ou imediatos de determinações metropolitanas, mas que continham, de fato, expectativas e interesses locais.

O último capítulo cobre a conjuntura dos principais tratados diplomáticos firmados por Espanha e Portugal na segunda metade do século XVIII, os quais repercutiram diretamente no desenho territorial das fronteiras amazônicas. As preocupações de ordem defensiva continuaram sendo um tópico recorrente da produção documental das autoridades radicadas em Maynas. Esses receios não eram apenas em relação aos avanços portugueses, mas igualmente contra distúrbios internos à América espanhola, como a rebelião indígena liderada por Juan Santos Atahualpa ${ }^{4}$ no Peru nos primeiros anos da década de 1740, temendo-se que tal levante atingisse a fronteira. A consciência da vulnerabilidade militar e precariedade econômica da Província de Maynas, insistentemente denunciada por religiosos, oficiais militares e autoridades civis locais, foi enfocada também por viajantes ilustrados, a exemplo de Charles Marie de La Condamine, que percorreu terras espanholas e portuguesas na América meridional. A partir de suas expedições na bacia amazônica, La Condamine também apontou a possibilidade de haver uma conexão fluvial entre o Amazonas e o Orinoco, o que significaria a existência de outras rotas de penetração portuguesa nas terras espanholas. As históricas investidas portuguesas, as possíveis novas rotas de penetra-

\footnotetext{
${ }^{4}$ Sobre a rebelião de Juan Santos Atahualpa, conferir: SANTOS GRANERO, Fernando. Anticolonialismo, mesianismo y utopía en la sublevación de Juan Santos Atahuallpa, siglo XVIII. In: Idem (compilador). Opresión colonial y resistencia indígena en la Alta Amazonía. Quito: Flacso-Sede Ecuador, 1992, p. 103-134; VARESE, Stefano. La sal de Los Cerros: Notas etnográficas e históricas sobre los campa de la selva del Perú. Lima: Universidad Peruana de Ciencias y Tecnologia, 1968.
} 
ção, somadas à "inoperancia estructural" (p. 212) da administração da fronteira formavam o cenário de insegurança da jurisdição espanhola sobre Maynas. A busca de uma resolução dos conflitos territoriais luso-espanhóis foi um dos aspectos centrais do Tratado de Madri de 1750, objetivando-se, a partir desse acordo, como salienta o autor, imprimir uma nova lógica de controle territorial e aproveitamento econômico dos espaços coloniais (p. 231). No caso dos limites luso-espanhóis ao norte, as novas delimitações propostas deveriam se guiar pelos principais rios da região, como o Caquetá/Japurá, Javari e Negro, estipulando-se ainda proibições ao contrabando e à circulação de pessoas entre as áreas portuguesa e espanhola da América. Mais uma vez, como destaca Sebastián Gómez, as determinações das cortes não encontravam amparo nas relações tecidas no espaço da fronteira, de maneira que as proibições estipuladas pelo tratado não poderiam ser efetivadas em uma zona marcada pela circulação de pessoas e pela prática rotineira do contrabando. Em relação aos limites luso-espanhóis do extremo norte, a anulação do Tratado de 1750 pelo Tratado de El Pardo (1761) apenas regulamentou um estado já vigente de inoperância local das regulamentações e controles determinados pelo Tratado de Madri.

Os ânimos belicistas novamente se levantaram com os ecos locais do conflito mundial representado pela Guerra dos Sete Anos (1756-1763), quando as autoridades lusas e espanholas das partes amazônicas se colocaram em prontidão para enfrentar uma possível guerra na fronteira. Nesse ponto, deve-se ressaltar a atenção de Sebastián Gómez para as formas de circulação de informações políticas na fronteira e sua importância para a conexão das remotas áreas amazônicas com as dinâmicas globais dos conflitos imperiais. Ainda na década de 1760, um impacto mais duradouro vivenciado em Maynas foi a expulsão da Companhia de Jesus. Em um prazo curto de tempo, na avaliação do autor, a saída dos jesuítas de Maynas facilitou as penetrações portuguesas em uma zona militarmente desprotegida, comprometendo ainda mais os interesses da Coroa espanhola naquele espaço.

Um esforço militar de maior envergadura para Maynas só viria a ser ensaiado nos anos de 1776-1777, em um contexto de conflitos imperiais no espaço atlântico e de enfrentamentos bélicos envolvendo espanhóis e portugueses em pontos limítrofes da América meridional. No mês de fevereiro de 1777, o vice-rei do Peru, Manuel Guirior, enviou uma ordem ao presidente da Audiência de Quito, Joseph Diguja, instando-o a organizar uma grande expedição militar destinada a Maynas. A chamada Expedição de Maynas deveria expulsar os portugueses das terras vizinhas, resolvendo definitivamente a favor da Espanha as pendências territoriais que há muito marcavam 
a bacia amazônica. Tratava-se de uma ação de grande porte pela logística militar e pelos recursos que consumiria (um valor estimado em mais de um milhão de pesos), mas que não foi concretizada em razão da chegada das notícias sobre as negociações luso-espanholas que redundariam no Tratado de Santo Ildefonso, assinado em outubro de 1777. O Tratado de Santo Ildefonso marcaria uma nova fase em Maynas, bem como um novo ímpeto aos projetos políticos e econômicos para as fronteiras do espaço amazônico, muito embora os trabalhos luso-espanhóis de demarcação nas décadas finais do século XVIII não tenham resolvido as pendências territoriais e as situações de conflitos de soberania. ${ }^{5}$

As fronteiras selváticas ao oriente dos Andes, limítrofes aos domínios luso-americanos, continuariam a representar uma barreira aos anseios estatais espanhóis de controle e modificação do espaço e de seus habitantes. As disputas mais amplas ocorridas no mundo atlântico repercutiam naquela distante zona de contato dos impérios ibéricos, ao mesmo tempo em que as relações tecidas propriamente no ambiente fronteiriço ditavam suas próprias regras e condições. De modo convincente, Sebastián Gómez González insere as remotas zonas noroccidentales nas lógicas imperiais do século XVIII.

Há pontos, porém, que permanecem como desafios aos pesquisadores que se dedicam ao estudo de uma área como a analisada pelo autor. Ainda é necessário entender, de maneira mais aprofundada, as percepções e os posicionamentos das comunidades indígenas na fronteira norte sobre as contendas e os jogos diplomáticos envolvendo os poderes monárquicos ibéricos. Alguns estudos mais recentes, referentes a outras áreas limítrofes na América ibérica, trazem contribuições significativas para a análise dessas questões, atentando para as aproximações e alianças estabelecidas entre indígenas e autoridades coloniais na construção das políticas imperiais para as fronteiras. Como exemplos, pode-se citar a pesquisa de Elisa Frühauf Garcia sobre a inserção dos indígenas nas disputas imperiais na fronteira meridio-

\footnotetext{
Sobre as demarcações luso-espanholas determinadas pelo Tratado de Santo Ildefonso na fronteira norte, ver os seguintes trabalhos: LUCENA GIRALDO, Manuel. La delimitación hispano-portuguesa y la frontera regional quiteña, 1777-1804. Procesos, Revista Ecuatoriana de Historia. Quito: Corporación Editora Nacional, n. 04, 1993, p. 21-39; RÍO SARDONIL, José Luis del. Don Francisco Requena y Herrera: una figura clave en la demarcación de los límites hispano-lusos en la cuenca del Amazonas (s. XVIII). Revista Complutense de Historia de América. Madri, n. 29, 2003, p. 51-75; TORRES, Simei Maria de Souza. Onde os impérios se encontram: Demarcando fronteiras coloniais nos confins da América (1777-1791). Tese de doutorado em História Social, PUC-SP, 2011.
} 
nal $^{6}$ e o estudo de Francismar Alex Lopes de Carvalho sobre os nativos e as políticas luso-espanholas para a fronteira entre Mato Grosso, Mojos, Chiquitos e Paraguai. ${ }^{7}$

No caso da obra de Gómez González, o autor traz uma análise documental embasada sobre as políticas tecidas e discutidas para a fronteira a partir da visão de militares, autoridades eclesiásticas e laicas que serviam na região, tanto do lado português quanto do espanhol. Contudo, o posicionamento dos índios ainda segue como uma questão a merecer maior atenção. Os indígenas certamente deveriam construir suas interpretações e suas expectativas políticas levando em consideração as relações imperiais que tinham aquela área como um dos seus mais problemáticos palcos de disputa. Claro que se trata de um assunto muito mais desafiador para o historiador, na medida em que a análise nesse caso deve recorrer a indícios por vezes esparsos disponíveis nos documentos sobre a região. Sobre a interseção de expectativas indígenas e imperiais na fronteira entre Maynas e a América lusa, algumas análises já foram desenvolvidas por Carlos Gilberto Zarate Botía, como em seu estudo sobre os índios Ticuna e suas relações com portugueses e espanhóis. ${ }^{8}$

Em todo caso, a obra de Sebastián Gómez González figura como um estudo de fôlego e, mais do que isso, um avanço para a compreensão mais complexa das relações tecidas pelos impérios ultramarinos no século XVIII. Para os pesquisadores da América espanhola, Gómez González coloca no mapa da produção historiográfica mais atual uma região tradicionalmente ignorada pelas grandes análises sobre a experiência de colonização espanhola do Novo Mundo. Para os historiadores brasileiros, por sua vez, sua obra ajuda a romper com paradigmas exageradamente regionalistas sobre a Amazônia.

\footnotetext{
${ }^{6}$ GARCIA, Elisa Frühauf. As diversas formas de ser índio. Políticas indígenas e políticas indigenistas no extremo sul da América portuguesa. Rio de Janeiro: Arquivo Nacional, 2009.

7 CARVALHO, Francismar Alex Lopes de. Lealdades negociadas: Povos indígenas e a expansão dos impérios ibéricos nas regiões centrais da América do Sul (segunda metade do século XVIII). São Paulo: Alameda, 2014.

8 ZÁRATE BOTÍA, Carlos Gilberto. Movilidad y permanencia Ticuna en la frontera amazónica colonial del siglo XVIII. Journal de la Societé des Américanistes, 1998 (1), p. 73-98.
} 


\section{Referências bibliográficas}

CARVALHO, Francismar Alex Lopes de. Lealdades negociadas: Povos indígenas e a expansão dos impérios ibéricos nas regiões centrais da América do Sul (segunda metade do século XVIII). São Paulo: Alameda, 2014.

ESPINOZA, Waldemar. Amazonía del Perú: História de la Gobernación y Comandancia General de Maynas (Hoy regiones de Loreto, San Martín, Ucayali y Provincia de Condorcanqui). Lima: Fondo Editorial del Congreso del Perú, 2007.

GARCIA, Elisa Frühauf. As diversas formas de ser índio. Políticas indígenas e políticas indigenistas no extremo sul da América portuguesa. Rio de Janeiro: Arquivo Nacional, 2009.

LUCENA GIRALDO, Manuel. La delimitación hispano-portuguesa y la frontera regional quiteña, 1777-1804. Procesos, Revista Ecuatoriana de Historia. Quito: Corporación Editora Nacional, n. 04, 1993, 21-39.

MARTIN RUBIO, Maria del Carmen. Historia de Maynas, un paraíso perdido en el Amazonas. Madri: Ediciones Atlas, 1991.

NEGRO, Sandra. Maynas, una misión entre la ilusión y el desencanto. In: NEGRO, Sandra E MARZAL, Manuel. Un reino en la frontera: Las misiones jesuitas en la América colonial. Quito: Abya-Yala, 2000, p. 185-20.

PORRAS P., Maria Elena. Gobernación y Obispado de Mainas, siglos XVII-XVIII. Quito: Ediciones Abya-Ayala, Taller de Estudios Historicos, 1987.

REIS, Arthur Cezar Ferreira. A política de Portugal no vale amazônico. Belém: Secult, 1993.

RÍO SARDONIL, José Luis del. Don Francisco Requena y Herrera: una figura clave en la demarcación de los límites hispano-lusos en la cuenca del Amazonas (s. XVIII). Revista Complutense de Historia de América. Madri, 2003, n. 29, 51-75.

ROSAS MOSCOSO, Fernando. Del rio de la Plata al Amazonas: El Perú y el Brasil en la época de la dominación ibérica. Lima: Universidad Ricardo Palma, 2008.

SANTOS GRANERO, Fernando. Anticolonialismo, mesianismo y utopía en la sublevación de Juan Santos Atahuallpa, siglo XVIII. In: Idem (compilador). Opresión colonial y resistencia indígena en la Alta Amazonía. Quito: Flacso-Sede Ecuador, 1992, p. 103-134.

TORRES, Simei Maria de Souza. Onde os impérios se encontram: Demarcando fronteiras coloniais nos confins da América (1777-1791). Tese de doutorado em História Social, PUC-SP, 2011.

VARESE, Stefano. La sal de Los Cerros: Notas etnográficas e históricas sobre los campa de la selva del Perú. Lima: Universidad Peruana de Ciencias y Tecnologia, 1968.

ZÁRATE BOTÍA, Carlos Gilberto. Movilidad y permanencia Ticuna en la frontera amazónica colonial del siglo XVIII. Journal de la Societé des Américanistes, 1998 (1), p. 73-98.

Recebido: 28/05/2015 - Aprovado: 13/10/2015 